\title{
Seeing smell
}

\author{
Holly Dugan
}

In January 2013, the Institute for Art and Olfaction commissioned graphic artist Micah Hahn and his design studio AutumnSeventy to create a series of prints on perfumery to commemorate its opening in Los Angeles. ${ }^{1}$ The result was Molecules, Series 1, which depicts three of the most influential molecules that defined twentieth-century perfumery - aldehyde C12, Iso E Super ${ }^{\circledR}$, and Galaxolide. ${ }^{2}$ Gilded and embossed, the prints emphasize the chemical structure of these molecules, even as it renders them as fine art. That the prints are also lightly scented with each aromachemical depicted on it emphasizes the broader, and one might say synaesthetic, take on the mission of the institute: to connect fine art with olfaction. Although it is a visual representation of molecules that define modern perfumery, Molecules, Series 1 thus joins a long art historical tradition of cross-modal representations of sensation, particularly smell.

Can a molecule be considered fine art? And, if so, which representation of that molecule best captures its olfactory beauty and renders it 'visible'? Consider, for example, Hahn's Galaxolide (Figure 3). It playfully invokes a wide variety of sensory modes to capture the aesthetic of Galaxolide. The print highlights both its chemical formula $-\mathrm{C}_{18} \mathrm{H}_{26} \mathrm{O}$ - and its structural formula. Both are linked to its cultural associations with perfumery and public health. Galaxolide is a second-generation polycyclic synthetic musk, discovered in the 1960 s, meant to synthesize the natural scent of deer musk. Translated into the language of public health, it is a hydrophobic but lipophilic 'toxin': it won't wash off in water and is easily stored in human fat. ${ }^{3}$ Rendered into the language of commercial perfumery, however, it smells 'clean', a 'musky, flowery, woody odor' with a 'sweet, powdery nuance'. ${ }^{4}$ Both its scent and its structure made it ideal for use in laundry detergents and soaps. And that association enables it to be a powerful 'note' in modern perfumes. What was known as the scent of Comfort brand laundry detergent became a key part of Estée Lauder's White Linen, Caron's Parfum Sacre and Ralph by Ralph Lauren. ${ }^{5}$

None of that history is easily visualized through either the molecular or chemical formula. But the print is also subtly scented with Galaxolide, connecting these visual representations with its olfactory counterpart and its many cultural 
[Image not available in this digital edition due to restrictions from the rights holder]

3 Micah Hahn, for the Institute for Art and Olfaction, 'Galaxolide', in Molecules Series 1 
associations. In doing so, the print playfully challenges its 'viewers' to consider whether or not perfume can be thought of as fine art by connecting olfaction with art historical traditions where vision is crucial. Staring at the embossed, shimmering representation of Galaxolide's structural bonds, breathing its scent of powdery, synthetic musk, one cannot help but wonder whether the union of art and olfaction necessarily demands a deeper interrogation of both categories and of the power of a synaesthetic approach to fine art. Scent emerges as a postmodern riff on what Benjamin famously defined as the 'aura' of certain objects, the 'semblance of distance' between object and viewer (regardless of their spatial proximity) and a form of perception that endows the object with an ability to 'look back at us,' as we 'breathe' in its wake. ${ }^{6}$ Modernity, especially its technologies of reproduction using film and video, shifted multisensorial, atmospheric, and synaesthetic modes of perception towards two-dimensional visual fields, seemingly sacrificing olfaction in the process. ${ }^{7}$ Exhibits that stage olfaction as part of the aesthetic experience redirect this more traditional 'view' of art appreciation towards a different aesthetic approach to design and materiality ${ }^{8}$ The aura of Molecules, Series 1 may very well be the effervescent scent that wafts from the print. But it is also its resonance with other cultural codes, codes that demonstrate the unspoken and powerful ways in which olfaction defines our interaction with the social worlds we inhabit.

The Institute for Art and Olfaction is not alone in making the claim that a molecule might indeed be fine art. In an attempt to emphasize the design of iconic perfumes like Chanel No. 5, Ficky, and Drakkar Noir (rather than the design of their containers), the Museum of Arts and Design in its The Art of Scent, 1889-2012 exhibition went to great lengths (and expense) to exhibit perfume as itself an art object, one that corresponds with other aesthetic movements. It may seem odd to classify Olivier Cresp's fragrance Light Blue (2001) as a still life, yet the exhibition did, asking visitors to perform a kind of olfactory ekphrasis - to think through the category of one medium (painting) to address another (perfume). In doing so, the object in question - and perhaps also the space of the museum itself - emerged anew, or at least that was the hope. Explaining that the problem of perfume's lack of aesthetic lustre connects to its status as a commodity, Chandler Burr, the exhibit's curator, emphasized that one kind of cross-sensory mode has stood in the way of others: the relationship between language and olfaction. ${ }^{9}$ Seeking to change the terms one uses to describe modern perfume, Burr's exhibition elevated scent through its association with the traditions of visual art.

Such an approach suggests the complex biological and cultural 'loops' through which we process sensation; some of these include aesthetic form while others engage more directly with lived experiences. ${ }^{10}$ To 'see' smell is thus to engage with a synaesthetic mode of art appreciation that probes the limits of both biological and cultural definitions of sensation. Though such an approach 
may seem impossible, synaesthesia - as both an embodied condition and an aesthetic trope - offers a useful reminder that sensation is always a cultural interface between the body and the world at large; it reminds us of the varied, multisensorial ways in which we have, and we might, perceive the world without insisting on ahistorical, trans-historical, or universally able-bodied experiences of embodiment. To 'see' smell in this way is to engage with both multisensorial meanings of art and olfaction in the present and a synaesthetic approach to their meanings in the past. As both Hahn's Galaxolide as well as The Art of Scent exhibition suggest, the art of olfaction and the olfactory components of art are not necessarily the same thing, which becomes immediately clear when one switches from modern or postmodern art objects to early modern examples.

Postmodern art like Hahn's Galaxolide is not the first to ask its audience to 'breathe' in its splendour or the scent of musk: many pre-modern objects were valued in Renaissance culture precisely for their redolent qualities. ${ }^{11}$ Of the wide variety of ingredients used to do this, musk was one of the most highly prized (and most expensive) scent-ingredient. Valued for its strength and its ability to be diffused, musk has been used to scent a wide variety of objects since late antiquity, though its value as a renaissance perfume ingredient derives more from its associations with the East than with the classical past. As early as the ninth century, Persia imported musk from the Tonkin region of Tibet and China through dedicated 'musk routes', routes similar to those of the Silk routes but connecting central and east Asia with the medieval Islamic world. ${ }^{12}$ From the Arabic misk, Persian mushk, and probably from the Sanskrit mushká for 'scrotum', musk was harvested from adult male deer, one of several species of Moschus, which produced musk in a vesicle near its genitals. Inside the vesicle, the animal's glandular secretions formed irregular 'grains' of musk. ${ }^{13}$ Once the deer was killed and the vesicle removed, these grains were dried preferably in their pod, developing a rich and distinctive scent. Used for thousands of years in Buddhist, Hindu, Jewish and Islamic rituals as both a perfume and a medicinal cure, musk was rediscovered by Europeans (along with other aromatic ingredients) through travel and trade associated with the crusades in the medieval period.

Though it is possible to remove musk without killing the deer, this was rarely done; musk deer were hunted to the point of endangerment. By the early nineteenth century, musk was in short supply and still in high demand, which led to experiments in domestication in the mid-nineteenth century. But the domesticated deer produced fewer musk grains and those had poor aromatic quality, which in turn fuelled its synthesizing after Albert Baur, a German chemist, seeking to develop a more effective version of trinitrotoluene (TNT), discovered one of his synthetic compounds smelled similar to musk. These early 'nitro' musks - musk ketone, musk acetate and musk xylene - were key components of major perfumes of the early twentieth century, including 
Chanel No. 5. ${ }^{14}$ Though their smell lacked the faecal quality of animal musk, their unique scent was highly valued in commercial perfumery. Nitro-musks, however, are highly unstable and potentially neurotoxic, which led to secondgeneration polycyclic musk synthetics like Galaxolide.

Hahn's Molecules 1 explicitly names Galaxolide, yet, for most of us, we see and smell musk. In this way, it offers a useful reminder of the wide variety of art objects that worked similarly in the past, resonating across cultural, chemical and art histories to create an aesthetic effect. Vision and olfaction have been linked in the past and remain linked in the present, a point brought home when one adds to this discussion the numerous pre-modern art objects associated with the history of perfume, many of which are on 'display' in museums because of their ornate materiality. Objects like gold censers, elaborately embroidered leather gloves, ceramic potpourri vases, ivory snuff boxes, silver vinaigrettes and the more familiar crystal and glass perfumer bottles are valued mostly for that visual materiality. That they were once defined by the long-since-faded scents they dispensed seems hard to reconcile within current cultures of display. Exhibited in ways that render them meaningful within modern and postmodern sensory hierarchies and emphasize their visual materiality, these objects' olfactory qualities are rendered obsolete.

Emphasizing visual strategies of display makes a certain amount of sense, given the educational goals and aesthetic objectives of most museums in Europe and North America. ${ }^{15}$ Objects must be exhibited in ways that render them meaningful to contemporary audiences. Although some museums are staging multisensorial exhibitions, including those that involve haptic and olfactory encounters, vision is still the dominant mode through which aesthetic beauty or cultural value is defined. ${ }^{16}$ The power to touch or smell an object is now associated with intimacy we associate with possession, because too many hands could potentially destroy that which makes it valuable. The object is preserved for the future by limiting access: sight, rather than touch or smell or taste, defines its display.

This was not always the case: both private and public collections often emphasized other sensory modes of display, fostering different kinds of understanding of an object's materiality. Many medieval and renaissance copies of the Holy Sepulchre, including the Jerusalem Chapel in Bruges and the Sacro Monte in Varallo, deliberately eschewed visual accuracy in favour of haptic, olfactory and gustatory sensory verisimilitude: this dampening of vision sought to mimic the sensory experience recorded by most Christian pilgrims to the Holy Sepulchre in Jerusalem, which could only be visited at night. ${ }^{17}$ Some renaissance art theorists believed that the aesthetic value of sculpture was best understood through touch: in fact Lorenzo Ghiberti in his fifteenth-century treatise on tactility in Italian sculpture argued that there were elements of sculpture only discernible through touch. ${ }^{18}$ Likewise, seventeenth-century 
collections designed to invoke curiosity about nature emphasized that all aspects of perception were needed to evaluate materiality. Edward Leigh, for instance, decried that fact that some numismatists evaluated a coin's worth by 'the base handling and smelling' better than 'others not altogether strangers to them could by sight'. ${ }^{19}$ Although Ken Arnold, historian and head of Public Programmes at the Wellcome Trust, emphasizes that this approach was not the norm, it was equally rare to find experts who did not rely on a multisensorial approach to materiality. Sensory perception was part of an emerging scientific method: Robert Hooke advised that the best way to examine an object studied was to evaluate its 'sonorousness or dullness, smell or taste'. ${ }^{20}$ And Renaissance collectors often encouraged visitors to take a sensuous approach to certain objects: early modern English diarist John Evelyn records his visit to the collection of Signor Septalla, when he smelled Indian wood 'that has the perfect scent of civet'. ${ }^{21}$ Robert Plot, naturalist, chemist and first keeper of the Ashmolean Museum, evaluated objects for the collection based on taste and smell, declaring one specimen worthy after ascertaining it was 'tart enough' and another after it had yielded 'a strong ungrateful smell'. ${ }^{22}$

Such an approach is counterintuitive to most contemporary cultures of display, which, of course, reflect modern ocular-centrism but also strategies for preservation: creating distance between objects and visitors helped to preserve many objects from the intense wear and tear that resulted from such handling it is hard to imagine allowing all visitors the opportunity to sniff the Mona Lisa. Though digital imaging and cataloguing has enabled museums to offer new modes of interaction, including digital reproductions that record the sound, feel and even smell of an object, it raises questions about the intrinsic value of the object's materiality. As Ken Arnold queries: 'If all the remote attributes of an object can be recorded and mastered elsewhere and all the direct ones matched and even surpassed through simulacra, why bother with the real thing at all?' Arnold and others emphasize that digital techniques are most effective when combined with experiences in situ, allowing museums to provoke wonder in much the same way as pre-modern cultures of display. ${ }^{23}$

Smell, as a mode of appreciating art and cultural objects, is generally associated more with an irreducible 'aura' of authenticity than with technologies of reproduction, seeming to offer a visceral truth about an encounter with art that seems more 'real' than others, especially those involving synthetic, technological or digital reproductions. But to take seriously the ways in which olfaction has participated in the history of art requires a more nuanced understanding of this visceral effect, particularly the ways in which it too has been culturally and historically constructed. Galaxolide, for instance, does not smell exactly like natural musk; it lacks a faecal quality. Yet this might be lost on most people who have not smelled it in its natural form. Modern perfume also involves a very different twist of space and time than what Benjamin evokes in his defini- 
tion of aura. It is designed to fade, and thus might be better likened to more ephemeral media such as performance art (as author Alyssa Harad has argued), or opera (as perfumer Christophe Laudimiel has explored in his 'scent opera'), or theatre (as the famous 'smell-o-vision' experiments of the 1960s argued, as did John Water's 'odorama' sniff cards that accompanied Polyester). ${ }^{24}$ Finally, we 'breathe' in much more than just the aura of art in the space of the museum, as experimental exhibits such as Laib's wax rooms or Martynka Wawrzyniak's 'Smell Me' olfactory self-portrait show. In this way, the ephemerality of scent connects to other kinds of contemporary art that challenge an aesthetic of permanence. $^{25}$

Staged in this way, perfume and its history connect these recent artistic movements to a longer, sensuous history of collection and display. As the perfume exhibit at the Museum of Arts and Design highlighted, it might itself be the 'object' on display, requiring a radical reconfiguration of the space of the museum and reminding visitors that aesthetic effects unfold in distinct time and space. Because scent is ephemeral, it also implicitly thwarts curatorial modes designed to emphasize preservation. Like other objects whose value may reside in the allure of use, especially those whose use we may no longer fully understand, the aesthetic of perfume is one that requires a different mode of appreciation. It reminds us that there is a 'beauty in letting go' of preservation, as archaeologist Sven Ouzman has argued, allowing new questions and relationships to form so that people may 'marvel at objects' but 'in ways that make the apprehender aware of the object's place in a continuum of humanistic and material practice' and of how their own perception of it is implicated in those histories. ${ }^{26}$

Early modern perfume had its own complex relationship to materiality; neither visible nor permanent, early modern perfume thwarts modern definitions of perceptible objects. Edmund Husserl, for instance, in his landmark study of phenomenology, argued that objects are things that can be handled, displayed and most importantly seen. ${ }^{27}$ Yet sensation as a historical phenomenon included a more complex approach to materiality than Husserl allows. For example, a fifteenth-century English censer highlighted in the Victoria and Albert Museum's 'Making Sense of an Object' series is, literally, defined by its olfactory use. ${ }^{28}$ Though it is implied by its name, its scent, frankincense, rarely accompanies its display; even if it did, modern frankincense stems from a different species of plant than either ancient or medieval frankincense. ${ }^{29}$ Its scent is closer to ancient rather than medieval incense. Likewise, our cultural associations with its smell may or may not be linked to Catholic liturgy; incense is a common note in modern perfumes, for example.

Yet to discount olfaction entirely is to misunderstand a large component of the object's history. English censers are almost always staged behind glass: objects like this one are incredibly rare, since most were destroyed in the many 
religious reforms of the sixteenth century. This particular example was found hidden in the walls of a house, where it was undoubtedly placed to protect it from such reform. In order to make sense of the object, the museum focuses on explaining its use through the conservation work involved in repairing its chains. The chains are key to understanding its complex cultural history: they facilitated its swinging, which was integral to its liturgical use. Frankincense and other resins were poured over hot coals placed inside the metal chamber, producing a sweetly scented smoke that emerged from the holes at its top; the smell marked the divine transformation of transubstantiation, signalling the presence of the divine.

Though small, it was a powerful dispenser, capable of filling even a cathedral with its scent. Although this one has little decorative detail, most medieval censers were shaped in the architectural form of the church, connecting their use with that space. ${ }^{30}$ Yet this object's scent history remains elliptical, reduced to its broken chains. The length of those chains, for instance, reveal if it was designed to hang or swing; by the late Middle Ages, censers had become larger, with four chains and an internal chamber to stabilize hot coals to better facilitate swinging. These advances all directly relate to more elaborate uses of liturgical incense, yet this particular object's worth is more readily measured through its visual materiality, a point that resonates in the tantalizing snippet of its history in the sixteenth century. How did it remain hidden in the walls of the house for so long, escaping detection when so many other censers did not? Its striking, historical narrative is left unanswered. It is easy to presume that, given its size, it was not easy to spot. Such a conclusion, however, fails to interpret the censer within other sensory registers: it left a rather large olfactory footprint. To make 'sense' of this object, one needs to grapple simultaneously with its tangible, visual and ephemeral materiality. Otherwise, our historical assumptions about the boundaries between visible and invisible matter obscures its material history: we value that which we can see (its metalwork, inscriptions, even donation history) rather than its aspects most familiar to late medieval men and women - its smoky, scented exhalations. How we define the materiality of our evidence matters, especially in attempts to collect, display or historicize material objects associated with the history of the senses. Put another way, one might ask: what does it mean to 'see' smell in the past after its materiality has long since faded?

Such a question is integral to understanding the history of early modern pomanders. Indeed, it is hard to argue that art and olfaction are not linked when considering the cultural history of early modern pomanders, yet it is equally difficult to say precisely how they connect to one another. Both were key to the power of pomanders within renaissance culture: part jewellery, talisman and medicinal cure, pomanders and the scents that defined them were integral to protecting those who wore them. Yet the relationship between the two - 
between a pomander's ornate exterior and the aromatics it contained - remains underexplored, particularly as an aesthetic one. Part of this has to do with the conventions of early modern art. As François Quiviger has argued, the relationship between these two sensory modes in Italian renaissance art is complex: flowers, for instance, are common allegories of both visual and olfactory beauty. Likewise, the sensory horrors of plague, particularly the stench associated with death, are rarely depicted visually, and are usually signified by a single figure, holding his nose. ${ }^{31}$ Beyond signifying a good or bad scent, what do visual clues signify? When olfaction is depicted extensively, it is often in foul detail. ${ }^{32}$

Elevated to allegorical abstraction or reduced to obscene fart jokes, olfaction remains an enigma within the aesthetics of early modern art. Pomanders, as decorative and scent objects, may provide some insight. Like censers, pomanders are literally defined by their olfactory use. From the French pomme d'ambre, or apple of amber, a pomander was a ball of aromatic paste, usually ambergris, musk or civet, mixed with other aromatics (floral petals, spices or animal secretions). Unlike most European renaissance censers, however, which were

[Image not available in this digital edition due to restrictions from the rights holder]

4 Pomander in the shape of a ship, the Walters Art Museum, Baltimore 44.464 
[Image not available in this digital edition due to restrictions from the rights holder]

5 Silver pomander in the form of a book, Science Museum A641827

[Image not available in this digital edition due to restrictions from the rights holder]

6 Pendant perfume-ball, British Museum AF.2863 
[Image not available in this digital edition due to restrictions from the rights holder]

primarily used by Catholic priests to dispense incense, renaissance pomanders varied greatly in both their scents and their uses. The term described a particular scent, but it became a complex signifier of perfume more generally along with the technology used to dispense it - by the fourteenth century the name also described the elaborate metal casings that contained them (and now define their storage and display).

These small, yet often ornate, objects exist in a wide range of forms; some hint at complex allegorical associations - such as the enamel seventeenth-century pomander in the shape of a ship (Figure 4), or the seventeenth-century silver pomander in the shape of a book with a rat engraved on its cover (Figure 5) while others are comprised solely of aromatics, such as the ball of benzoin studded with emeralds (Figure 6), or designed to protect and dispense a similar mass of aromatics (Figure 7). Pomanders like these last two examples were made up of a simple and often costly mass of aromatic paste made from amber-gris, benzoin, civet, musk, or some amalgamation of these ingredients; others most likely housed a more affordable paste made from floral petals and fixatives. 
Even the most simple of pomanders in terms of design, however, may provide some insight into both its scents and their cultural uses. Those affixed with gemstones may have served as aromatic jewellery, hanging from belts or necks and perfuming the wearer and his or her clothes; its elevated ornamentation emphasizes the costliness of the aromatics most likely contained within it. The more elaborate the container, one presumes, the more expensive its ingredient (with musk generally the costliest of aromatic ingredients). Some, carved out of wood with simple cutouts as design elements, were most likely used in prayer, hanging from rosary beads made from a similar paste as that inside - ground rose petals mixed with aromatic fixatives. These rose-scented pomanders and beads fostered multisensorial (haptic and olfactory) meditation on the Virgin Mary, whose purity was allegorically linked to the rose. To 'see' this particular smell in renaissance art requires we look for it using synaesthetic clues to its material history rather than its allegorical signification. Bartholomäus Braun's Portrait of a Woman (1547), for example, depicts its subject in prayer, holding just such a pomander and rosary beads, its scent seemingly signalled by a floral attribute placed nearby. Yet the flower is a pink carnation, not a rose; its presence works in visual, rather than olfactory ways, suggesting both the young woman's faith and, most likely, her recent betrothal..$^{33}$ The scent of the rose resonates through the colour of the red rosary beads that are entwined through her fingers, a pinky extended towards the pomander.

That extension may be figurative, but such a gesture also subtly connotes how these objects were used. A pomander needed to be opened or set in motion to release its scent. Worn close at hand, hung from chains around the neck and waist, pomanders were thus both decorative and utilitarian. This unique combination of visual form and olfactory function created intimate, aesthetic effects, linking a pomander's visual and olfactory qualities through an intimate, and haptic, engagement with both. Only part of its cultural value emerges through static display. Pomanders that work as memento mori, for instance, engage directly with anamorphic perspective; the handling required to achieve the desired visual effect undoubtedly released fragrance, raising questions about how that scent connected to the aesthetic representation unfolding for the viewer. The Danish pomander (circa 1600) that later belonged to Queen Sophie Amalie of Denmark, for instance, visually mimics the bright red colour of rosary beads, but its six 'beads' are made instead from red coral, four of which are carved into the shape of skulls - something its owner would have known intimately by touch. The remaining two beads explicitly connect beauty with death, with one side carved with an image of a crowned woman and the other a crowned skull. These beads are strung on a chain with an enamel pomander of double their size shaped as a skull, crowned with rubies. Inside it are six compartments, engraved with scent ingredients - 'schlag', 'canel', 'citron', 'malorca', 'rosen' and 'negelen' [musk, cinnamon, lemon, orange, rose and clove] - as well as a 
sponge for a vinaigrette. ${ }^{34}$ The vinaigrette released its scent with every twist and turn of the chain; the internal compartments contained specimens useful to have at hand should disease and death manifest itself in something other than allegorical form.

The Danish queen's 'death's head pomander/vinaigrette' performs a visual and olfactory twist on pomanders of prayer even as it worked as medicinal protection from foul airs. ${ }^{35}$ Pomanders were often shaped as memento mori, adding additional olfactory meanings to their visual signification. One sixteenthcentury example demonstrates how this worked: on one side is engraved the face of a woman, on the other, a skull. It warns those who read its engraving 'sum fui'. Yet the perfume it contained also complicates this temporal narrative, infusing it with an even more sinister meaning: in this instance, the scent of the pomander works as an olfactory reminder of the visual lesson - beauty not only fades but is perhaps already dead, since the fragrance emerges only from dead or dried botanical and animal matter. The anamorphic perspective required to 'read' the memento mori's warning engages the pomander's scent: one heeds the warning only after breathing in the pomander's scent. 'Sum' is engraved on the woman's throat; ' $f u i$ ' on the top of the skull. This oddly asymmetrical placement of text requires that one turn and flip the pomander in order to read the message, which might be explained by the fact that the empty eye sockets of the skull open to the inside, allowing scent to escape from them during this action. ${ }^{36}$

That a sweet smell could signal the presence of disease and death was a paradox all too real for most early modern men and women; plague prevention required extensive use of aromatics to protect the body's vulnerable orifices from contagion. Pomanders worked especially well when patterns of contagion were erratic, as they often were in England; although some geographic areas were linked with higher threats of contagion, and some plague outbreaks were more uniform than others, for the most part dangerous air could be anywhere, requiring one have perfumed protection close at hand. ${ }^{37}$ Strong scents worked as a shield, blocking more dangerous, contaminated air from entering the body. Yet this practice ironically worked to connect perfume with the presence of plague, linking the fragrant with the foul in complex and nuanced ways. Pomanders, as memento mori, enact this paradox in highly ornate ways. Shaped into coffins and skulls, these pomanders connected the technology of perfume with the latent risk in smelling. The olfactory paradox of smell - that death might smell sweet - is revealed through its visual form. Other images emphasize the paradox of its size in relationship to its cultural necessity. Pomanders were often shaped as snails, which seems abstract until one considers the animal's ability to withdraw into itself for self-protection. Snails were thus a symbol of the pomander's power: though one could not retreat from the disease, one could retreat into one's own air. ${ }^{38}$ Its perfumes were thus an extension of the self, rather than a mode of self-presentation for others. Such a conclusion helps 
[Image not available in this digital edition due to restrictions from the rights holder] 
explain a seventeenth-century English pomander in the shape of a woman's head (Figure 8): it may have served as a self-portrait, connecting the pomander's scents with those that protected its young wearer from harm.

Given their use, some pomanders were affixed with written amulets: one Birgittine nun sent gifts of musk-scented pomanders to her friend and her children to defend them from the bad vapours associated with the plague. Noting their small size - she calls them bisamäpfelien or 'little musk apples' the nun also notes that each was affixed with a feather that contained a scroll of paper with the Greek letter tau written on it. As art historians Corine Schlief and Volker Schier argue, a letter that accompanied this gift suggests the expan-siveness of 'sensory and cognitive experiences' that comprised the 'spiritual and material life' that comprised the everyday life of the faithful..$^{39}$ In it, the nun explains how the gift was intended to engage all of the senses of its wearer: the feather reminds the wearer of its hidden, written scroll (inscribed with its symbol of the cross), a symbol of everlasting life in the presence of death just as the sweet scent of musk promised to defend against any 'bad vapours'. Its small size perhaps suggests its intimacy; it may reflect a private, but powerful bond between women. Such epistolary evidence documents that seeing, smelling and feeling the pomander rendered it meaningful as a gift.

Some pomanders have internal compartments that are engraved with the names for various spices and aromatics. This sixteenth-century example (Figure 9), for instance, includes engraved compartments for 'moscat', 'rosen' and 'rosemarin' (nutmeg, rose and rosemary), with images of foliage on its internal

[Image not available in this digital edition due to restrictions from the rights holder]

9 Gilt pomander, Science Museum A629413 
sides. Outside it is also decorated with images of fruit and foliage. The emphasis on spices - rather than more costly aromatics such as civet, musk or storax suggests that this object was valued less for its scent ingredients and more for its cultural use, though such a conclusion limits the design of the object to our ability to 'read' its olfactory materiality through the engraved names alone. Could its more abstract qualities suggest something else? The emphasis on fruit and foliage suggests a correspondence with the botanical scents and spices contained within it. Might the pomander's scents be meant to work together in a cohesive way? Some have argued that the complexity of this design suggests that they were not; separate chambers require more time to open the pomander and then select an internal chamber to open and inhale. ${ }^{40}$ This seems to be a very different action than merely sniffing an open-work pomander that protects an aromatic ball of paste. But what one loses in immediacy, one gains in specificity, raising questions about the cultural significance of specific scents. For this style of pomander, the named scent of rose or musk may signal a complexity of signification akin to those of Galaxolide discussed above.

And what of pomanders that use engravings to differentiate between compartments? One, for instance, has four compartments, each side engraved with an images of a saint - Dorothy, John, Barbara, Andrew, Mary Magdalene, Paul, Catherine and Peter. ${ }^{41}$ When closed it forms an image of a sky, with a sun and clouds. As one cataloguer notes, it resembles a prayer nut when closed, an object that drew upon medicinal traditions based on morphology as well as sensuous prayer rituals. ${ }^{42}$ Do these visual clues work in cross-modal ways as well - do they 'signify' scents? Did St Catherine of Alexandria - often invoked in early modern Catholic art as a protector of virginity - connect with nutmeg, cloves and balsam, scents associated with the Virgin ${ }^{33}$ Though it is not depicted on the pomander, St Dorothy's attribute of apples and roses may have been signalled through the presence of scent.

In this chapter, I have surveyed only a few of the many early modern pomanders housed in private and public collections. Though they vary greatly - in design, ornamentation and provenance - most share one thing: they are now empty. To understand the cultural signification of early modern pomanders thus requires a synaesthetic approach: we must train ourselves to 'see' smell in the past. Pomanders, like most objects in museums, are catalogued, displayed and organized to make meaning within our sensory world. We define them primarily by their visual components; as a result they join a variety of other objects stacked in drawers and displayed behind glass whose meanings remain occluded; to understand their meaning in the past is to engage with a multisensorial approach to history. In this way, pomanders remind us of the complex ways in which olfaction challenges traditional approaches to materiality and representation. To see smell in the twentieth and twenty-first centuries involves fine arts and photography, the chemicals that we recognize as perfume 
transcribed into abstraction, either through elevating their chemical bonds into gilded prints or capturing their reaction through photography. The synaesthetic loop is visual; early modern pomanders may have worked in a similar way but they also engaged haptic and perhaps even gustatory meanings as well as sensory modes vastly different from our own. We may not be able to access those meanings, but to view, hear, touch, taste or smell an object is to wonder about those sensorial meanings as they unfolded in strikingly different times and places. I can attest that it is a very different experience to hold and sniff an early modern pomander, given its historical association with plague, than to view it. Even the absence of scent reminds us of its once potent power; the act of sniffing is itself a potentially fraught, yet unavoidable action. As such, pomanders remind us not only of the strong links between art and olfaction in our own cultural moment, but also of their connection in the past. They challenge us to engage in a synaesthetic approach to materiality so that we might begin to approach a multisensorial understanding of history.

\section{Notes}

1 For more, see the institute's website http://artandolfaction.com/special-projects/ molecule-prints/ [accessed 18 June 2013].

2 Aldehyde C12 is best associated with the fizzy, sparkly scent of Chanel No.5; Iso E Super is the trademarked name of 7 -acetyl, 1,2,3,4,5,6,7,8-octahydro-1,1,6,7-tetramethyl naphthalene, a woody-amber scent (when combined with other molecules) and a clean scent (on its own) that is used in so many modern perfumes that it is hard to label one as representative; Galaxolide is a synthetic musk used in perfumes like Tresor and White Linen.

3 For the extent to which it has been found in humans, see the Environmental Working Group's Human Toxome Project www.ewg.org/sites/humantoxome/ [accessed 13 June 2013].

4 See perfume blogger Elena Vosnaki's essay on musk http://perfumeshrine.blogspot.com/2009/12/musk-series-2-natural-and-everything.html [accessed 13 June 2013].

5 Vosnaki, http://perfumeshrine.blogspot.com/2009/12/musk-series-2-naturaland-everything.html [accessed 13 June 2013].

6 Walter Benjamin, 'Little History of Photography', trans. by Jephcott and Kingsley Shorter, $S W, 3: 104$, cited in Miriam Hansen's 'Benjamin's Aura', Critical Inquiry, 34 (2008): $336-76$ (p. 340).

7 For more on synaesthisa and modernist art, see Caro Verbeek's research: www. caroverbeek.nl.

8 For more on directed viewing, especially of the productive arts, see Caren Yglesias, 'Seeing Air', Visuality/Materiality: Images, Objects, and Practices (Farnham: Ashgate, 2012), pp. 85-108 (p. 87).

9 “"To a degree it's a problem of language", Mr Burr said. "We have not had anything other than a marketing language applied to these works." Quoted in Carol Kino, 'Fragrances as Art, Displayed Squirt by Squirt', New York Times, 15 Nov. 2012 
www.nytimes.com/2012/11/16/arts/design/the-art-of-scent-at-the-museum-ofarts-and-design.html? pagewanted $=$ all [accessed 19 June 2013].

10 David Howes, 'Introduction', in Empires of the Senses: The Sensual Culture Reader, ed. by David Howes (Oxford: Berg, 2005), p. 5; see also his essay, 'Hearing Scents, Tasting Sights: Toward a Cross-Cultural Multi-Modal Theory of Aesthetics', in Art and the Senses, ed. by Francesca Bacci and David Melcher (Oxford: Oxford University Press, 2011), pp. 161-81.

11 Holly Dugan, Ephemeral History of Perfume: Scent and Sense in Early Modern England (Baltimore, MD: Johns Hopkins University Press, 2011), pp. 6-7.

12 Ronit Yoeli-Tlalim, 'Islam and Tibet: Cultural Interactions - An Introduction', in Islam and Tibet: Cultural Interactions Along the Musk Route, ed. by Anna Akasoy, Charles S. Burnett and Ronit Yoeli-Tlalim (Aldershot: Ashgate, 2011), pp. 1-16 (p. 8).

13 R.A. Donkin, Dragon's Brain Perfume: An Historical Geography of Camphor (Leiden: Brill, 1999), p. 2; Anya King, 'Tibetan Musk and Medieval Arab Perfumery', in Akasoy, Burnett and Yoeli-Tlalim (eds), pp. 145-62 (p. 147).

14 Tilar Mazzeo, The Secret of Chanel No. 5: The Intimate History of the World's Most Famous Fragrance (New York: Harper Collins, 2010), p. 208.

15 See Constance Classen and David Howes, 'The Museum as Sensescape: Western Sensibilities and Indigenous Artifacts', in Sensible Objects: Colonialism, Museums, and Material Culture, ed. by Elizabeth Edwards, Chris Gosden and Ruth Phillips (Oxford: Berg, 2002), pp. 199-222 (p. 200).

16 Other exhibits have worked from the opposite premise - that scent can expand our experience of visual art. Tate Britain's Pre-Raphaelites: Victorian Avant-Garde exhibit, for example, included an ambulatory 'scent' tour, led by art historian Christina Bradstreet and olfactory event planner Odette Toillete, whose goal was 'to explore the historical associations of scent and its influence upon the interpretation of the paintings'. See 'Scented Visions: A Multisensory Tour of the Pre-Raphaelites Exhibition and PrivateView', www.tate.org.uk/whats-on/tate-britain/private-viewspecial-event/scented-visions-multisensory-tour-pre-raphaelites [accessed 13 June 2013].

17 Laura Gelfand, 'Sense and Simulacra: Manipulation of the Senses in Medieval Copies of Jerusalem', Postmedieval, 3 (2012), 407-22.

18 'I have seen by diffused light ... a statue of an Hermaphrodite ... which had been made with admirable skil ... In this [statue] there was the greatest refinement, which the eye would not have discovered had not the hand sought it out', Lorenzo Ghiberti, I Commentari, ed. by O. Morisani (Naples: Riccardo Ricciardi, 1947), pp. 54-55, quoted in Geraldine A. Johnson, 'Touch, Tactility, and the Reception of Sculpture in Early Modern Italy', in A Companion to Art Theory, ed. by Paul Smith and Carolyn Wilde (Oxford: Blackwell, 2002), pp. 61-75 (p. 64).

19 Edward Leigh, Three Diatribes (1671), p. 42, cited in Ken Arnold, Cabinets for the Curious: Looking Back at Early English Museums (Aldershot: Ashgate, 2006), p. 76.

20 Robert Hooke, Posthumous Works of Robert Hooke, ed. by Richard Westfall (New York: Johnson Reprint Corp., 1969), p. 36.

21 John Evelyn, Diary of John Evelyn, Esq., ed. by William Bray (London: Bickers, 1906), p. 275. 
22 Arnold, p. 56.

23 Arnold, p. 256.

24 Alyssa Harad, 'Perfume is Not an Object: A Few Thoughts', www.alyssaharad.com/ scent/perfume-is-not-an-object-a-few-thoughts-about-perfume-and-art [accessed 1 May 2013]; Christophe Laudamiel, Nico Muhly and Valgeir Sigurdsson, 'Green Aria Scent Opera'; for more on smell-o-vision and Polyester, see Rachel Herz, Scent of Desire: Discovering our Enigmatic Sense of Smell (New York: Harper Perennial, 2007), p. 230.

25 See Helen Pheby, 'Contemporary Art', in Museum Materialities: Objects, Engagements, Interpretations (New York: Routledge, 2010), pp. 71-88 (p. 81).

26 Sven Ouzman, 'Beauty of Letting Go: Fragmentary Museums and Archaeologies of Archives', in Sensible Objects: Colonialism, Museums, and Material Culture, ed. by Elizabeth Edwards, Chris Gosden and Ruth B. Phillips (Oxford: Berg, 2006), pp. 269-301 (p. 293).

27 Edmund Husserl, 'A Phenomenology of Reason', in General Introduction to a Pure Phenomenology (The Hague: Nijhof, 1982), p. 31.

28 See 'Censer: Making Sense of an Object', in Conservation fournal, 39 (2001), www. vam.ac.uk/content/journals/conservation-journal/issue-39/censer_making_ sense_of_an_object/hduga [accessed 24 June 2013].

29 Dugan, p. 31.

30 Fifteenth-century Florentine censer, Victoria and Albert Museum, no. 549-1889.

31 François Quiviger, The Sensory World of Italian Renaissance Art (London: Reaktion, 2010), pp. 126, 134.

32 Alice Sanger and Siv Tove Kulbrandstad Walker, 'Introduction: Making Sense of the Senses', in Sense and the Senses in Early Modern Art and Cultural Practice, ed. by Alice Sanger and Siv Tove Kulbrandstad Walker (Farnham: Ashgate, 2012), pp. 1-16 (p. 14 n. 4).

33 See Maryan Ainsworth and Joshua Vaterman, German Paintings in the Metropolitan Museum of Art, 1350-1600 (New York: Metropolitan Museum of Art, 2013), p. 283 n. 10 .

34 Danish Royal Collection, Rosenborg Palace, Copenhagen, http://dkks.dk/Pomander-2 [accessed 2 July 2013].

35 The titles of both Richard Whitford's Pomander of Prayer (1531) as well as Thomas Becon's Pomander of Prayer (1563) suggest that the term also accrued literary and metaphorical meanings in the sixteenth century.

36 Edmund Launert, Perfume and Pomanders: Scent and Scent Bottles (Munich: Potterton, 1987), p. 110.

37 Dugan, pp. 110-11.

38 Launert, p. 22.

39 Corine Schlief and Volker Schier, Katarina's Windoms: Donation and Devotion, Art and Music, as Heard and Seen in the Writings of a Birgittine Nun (State College, PA: Penn State University Press, 2009), p. 241.

40 Luisa Coscarelli, 'Do I Smell? The Pomander and its Materiality', Unmaking Things: 2012-2013, Royal College of Art and Victoria and Albert Museum http:// unmakingthings.rca.ac.uk/2013/do-i-smell-the-pomander-and-its-materiality/ [accessed 21 June 2013]. 
41 Launert, p. 106.

42 Launert, pp. 20, 106.

43 C.M. Woolgar, The Senses in Late Medieval England (New Haven, CT: Yale University Press, 2006), p. 243. 